\title{
Knowledge, Attitude and Practices about Quality and Management of Anthelmintic Drugs in Adea Berga District, Central Ethiopia
}

Bayisa Duguma ${ }^{1}$, Birhanu Abera $^{2}$, Yimer Muktar $^{1}$, Simegnew Adugna ${ }^{1 *}$, Hailemariam Kefyalew ${ }^{1}$ and Shimelis Mengistu ${ }^{1}$

${ }^{1}$ College of Veterinary Medicine, Haramaya University, PO Box 138, Dire Dawa, Ethiopia

${ }^{2}$ Holeta Agricultural Research Center, Holeta, Ethiopia

"Corresponding author: Simegnew Adugna, College of Veterinary Medicine, Haramaya University, PO Box 138, Dire Dawa, Ethiopia, Tel: +251-25-5530334; E-mail: adusim@yahoo.com

Rec date: April 24, 2018; Acc date: May 17, 2018; Pub date: May 18, 2018

Copyright: (c) 2018 Duguma B, et al. This is an open-access article distributed under the terms of the Creative Commons Attribution License, which permits unrestricted use, distribution, and reproduction in any medium, provided the original author and source are credited.

\begin{abstract}
The efficacy of anthelmintic is affected by incorrect dosage, exclusive use of drugs of the same mode of action, substandard quality drugs, and inappropriate handling. Questionnaire survey was administered to 384 farmers to assess the awareness level of farmers about practices in relation to quality and management of anthelmintic drug in Adea Berga district, Central Ethiopia. A total of 384 farmers were contacted, $69 \%$ of the respondents were males while $31 \%$ were females. The majority of interviewees were uneducated $(63 \%)$ and $77.6 \%$ of the respondent had awareness about the drug store. Of the interviewees, majority of them had no enough knowledge about safe handling and its management. $59.5 \%$ of the respondent bought the drugs from veterinary clinic and $78.3 \%$ kept the drugs at room temperature that compromise the quality of the drug. Majority of the respondents (87.5\%) obtained the information about drug administration from professionals and $86.5 \%$ of the respondents were consult nonprofessionals to administer the drug to animals. Majority of the farmers $(93.8 \%)$ practice deworming. $72.4 \%$ of the study participants were calculate the dose of the drug by guess based on age and the size of the animal and $28.8 \%$ were given over and under dose of the drug respectively. $15.8 \%$ and $4.9 \%$ were explained about the cause of over dose as severe diarrhea and death of the treated animal but most $(77.9 \%)$ of the farmers responded as there were doubtful with under dose. $70.6 \%$ and $75.8 \%$ of the participants revealed that the challenges faced when they bought the drugs from public and private shops as the distance and the cost as major issue respectively. Therefore, continuous awareness creation works to the community, training on safe veterinary drug handling and drug administration and sustainable improvement of animal health service delivery through a well-regulated private service.
\end{abstract}

Keywords: Adea Berga; Drug quality; Effectiveness; Drug handling; Dose

\section{Introduction}

The Animal medicines play an important role in the control and prevention of disease and animal suffering but have the potential to cause harm if not used properly [1]. Veterinary drugs are used in livestock sector either rationally or irrationally as therapeutic, prophylactic, and growth promotion. Rational use of drugs are based on the use of right drug, right dosage, right cost and at right time which is well organization [2] whereas irrational use of drugs is as "too many medicines are prescribed per patient, injections are used where oral formulations would be more appropriate, anthelmintic are administered in inadequate doses or duration, prescriptions do not follow clinical guidelines and self-medicate inappropriately or do not adhere to prescribed treatment" [3].

Due to lack of effective helminth control strategies for cattle in Ethiopia, antihelminthics are misused. Misuse and smuggling of anthelmintic in many forms, such as illegal sales in open markets and irrational administration, is widespread in Ethiopia. In addition, due to the absence of a rational policy for anthelmintic use, methods that can preserve and maintain the efficacies of anthelmintic were not well practiced [4,5]. Ineffectiveness takes several forms, such as medicines containing less than the stated dose of the active ingredient or containing unstated or harmful substance. Similarly fake or counterfeit medicines and medicines that have been degraded or adulterated due to improper storage and handling may be ineffective [6]. Hence, the health ministries of many countries, especially developing nations, struggle to prevent the circulation of substandard and counterfeit medicines [7].

Medicinal products and starting materials used in the manufacture of medicinal products should be stored and transported under conditions which ensure that their quality is maintained. Manufacturers' recommendations concerning storage temperatures should be observed and this may involve the use of specialized storage and transport facilities. Temperature-monitoring devices should be used to demonstrate compliance with the designated temperature ranges [8].

Subclinical gastrointestinal parasite infections are among the major health problems limiting the productivity in dairy animals which is explained by economic losses through lowered fertility reduced work capacity, involuntary culling and reduction in food intake, reduced weight gain, lower milk production, treatment costs and mortality in heavily parasitized animals [9]. Parasites also have a negative effect on immunity [10]. The prevention and control of helminth parasites is not based on disease epidemiology rather is targeted to treat sick individual animals [11].

Most of the farmers and individuals who use anthelmintics, carried reports that question the quality of medicines circulating in the local market. The report includes especially poor quality, non-efficacious 
and counterfeits drugs in the pharmaceutical markets. Market authorization allows a medicine to be placed in the market. The consumer identifies with its potency to relieve or heal. In most cases, this spurs production of generics to compete with innovator products. Most worrisome, is that it also attracts counterfeiting. Once a drug is manufactured, the onus is on the manufacturer to supply the regulator with any new information on the product such as new uses and new adverse effects, as well as changes in manufacturing sites, ingredients and processes. Most of the African countries the registration of drugs must be renewed every five years [12].

According to the WHO definition, if a drug upon laboratory testing fails to meet those specifications it is classified as a substandard drug. The term substandard is used to describe the quality status of genuine drugs produced by legitimate manufacturers and the quality of drug substances and medicinal products is determined by their design, development, in-process controls, good manufacturing practice, and process validation, and by specifications applied to them throughout development and manufacture [13].

Anthelmintic drug quality and its management practice become a worldwide problem especially in developing countries. But, until recently, there was little or no documented research that can address these issues. However, countries with livestock numbers comparable to ours have reported occurrences of anthelmintic drug abuse, misuse, smuggling and substandard drugs in areas where cattle producers extensively used anthelminthic. There was limited information about knowledge, attitudes and practices in relation to the drug quality and management in the study area and also drug quality and its management is a potentially costly problem and continue to be a concern $[11,14]$.

Therefore, the objective of this study was to assess the level of farmer's knowledge, attitude on anthelmintic drugs management practices in relation to drug quality.

\section{Materials and Methods}

\section{Study area description}

The study was conducted from November 2016 to May 2017 in Adea Berga district, located around $72 \mathrm{~km}$ west of Addis Ababa. The area lies at longitude $38^{\circ} 30^{\prime} \mathrm{E}$ and latitude $9^{\circ} 3^{\prime} \mathrm{N}$ and includes highland and midland agro-ecologies with an altitude at about 2600 meters above sea level. The site is characterized by cool sub-tropical climate with mean maximum and minimum temperatures of $26^{\circ} \mathrm{C}$ and $10^{\circ} \mathrm{C}$ respectively with mean relative humidity of $59 \%$. The mean annual rainfall ranges from 800 to 1400 milliliters [15].

\section{Study design}

A cross-sectional study was conducted to evaluate awareness, attitude and practices of the household head attendants towards anthelmintic drugs quality and management issues and to identify the drug quality problem in the district. A questionnaire was administered to all households. The survey questioner were first created in English language and translated orally into the local language (Afan Oromo) at the time of survey, to ensure that the English and local language versions carried the same meanings and disseminated by face to face interview method on the districts. Whenever the head of a household was present, he/she was interviewed otherwise a present adult household member was interviewed. The questionnaire was designed in a structured manner with closed questions to obtain quantitative data for the analyses.

\section{Study populations and sampling methodology}

The study was conducted in Adea Berga district. The study population was selected on the basis of availability during the time of study. For selection of respondents, details of Adea Berga and its kebeles were obtained from the data available in wereda and kebeles. 12 administrative units (locally called kebele) were purposely selected based on their distance from total list of administrative units and the complaint from farmers on drug quality problem. Accordingly, a total of 384 farmers were surveyed. The numbers of respondents from each kebele were determined based on size of kebele and its population size.

\section{Questionnaire survey}

A semi-structured questionnaire was prepared to gather information about the potential risk factors and awareness of the participants about knowledge, attitude and practices in relation to quality and management of anthelmintic drug and it contained mostly closed-ended questions to ease data processing, minimizing variation and improve precision of responses. This questionnaire was administered to 384 participants. The questions in the questionnaire included sex (male, female), age (20-35 years, 36-45 years and 46-70 years) educational status (primary, secondary and illiterate), awareness about drug store (yes/no), drug prescription (yes/no), method of keeping drug (at room temperature, anywhere), information about drug administration (from professional, leaflet), about the source of the drug (Veterinary clinic, open market and vendor, drug pharmacy), who administer the drugs (professional, none professional), deworming practice (yes/no) frequency of deworming (every for production, 3-4 months, to treat disease), knowledge about dose calculation (guess based on age and size, advice from professionals), administration of over dose (yes/no), problem of over dose (severe diarrhea, inappetance, death, no problem), use of under dose drug (yes/no), problem of over dose (fail to cure, doubtful, no problem) were documented during the field survey.

\section{Statistical Analysis}

All responses were exported to Microsoft Excel (Microsoft Windows version 2010). Then the recorded questionnaires were analyzed using statistical package for social sciences (SPSS) version 20 and were evaluated descriptively.

\section{Results}

The predominant age group among the respondents is 36-45 years (54\%), then 20 -35 years (28\%) and while above 45 years age group made up only (18\%) of the respondents. In total 67 (31\%) individuals were female and $317(69 \%)$ were male that provided information on the way of anthelmintic drug use and handling method. Most respondents held on the area were illiterates, $242(63 \%)$ and the rest were educated, 142 (37\%). In total of 142 educated respondents, 104 (27.1\%) individuals were educated primary school, while 38 (9.9\%) were educated high school as summarized in Table 1.

In the present study 360 (93.8\%) individuals deworm their animals whereas $24(6.2 \%)$ individuals were not deworm their animals. 247 $(64.3 \%)$ of respondents used anthelmintic every time as growth promoter, $93(24.2 \%)$ of respondents used anthelmintic from 3-4 
Citation: Duguma B, Abera B, Muktar Y, Adugna S, Kefyalew H, et al. (2018) Knowledge, Attitude and Practices about Quality and Management of Anthelmintic Drugs in Adea Berga District, Central Ethiopia. J Vet Sci Technol 9: 540. doi:10.4172/2157-7579.1000540

Page 3 of 6

months for deworming strategically and 44 (11.5\%) purposely used anthelmintic for treating of diseased animals.

\begin{tabular}{|c|c|c|c|c|}
\hline S. no & Demography & $\begin{array}{l}\text { Response } \\
\text { categories }\end{array}$ & $\begin{array}{l}\text { Frequency } \\
\text { (N) }\end{array}$ & Percentage (\%) \\
\hline 1 & \multirow{2}{*}{ Sex } & Male & 317 & 69 \\
\hline 2 & & Female & 67 & 31 \\
\hline 3 & \multirow{3}{*}{ Age } & $20-35$ years & 102 & 28 \\
\hline 4 & & $36-45$ years & 222 & 54 \\
\hline 5 & & $46-70$ years & 60 & 18 \\
\hline 6 & \multirow{3}{*}{ Education status } & Primary & 104 & 27.1 \\
\hline 7 & & Secondary & 38 & 9.9 \\
\hline 8 & & Illiterate & 242 & 63 \\
\hline
\end{tabular}

Table 1: Percentage distribution of the demographic data of the respondents.

A higher percentage of respondents (86.5\%) use anthelmintics without consulting a veterinarian. Instead they follow the commitment obtained from clinics or from the seller and the rest of the respondents read and follow the leaflet instructions (Table 2). 278 (72.4\%) of respondent stated to adjust dosage according to size and age of the individual animals and the remainder $106(27.6 \%)$ of respondent follow the advice from professionals. Majority of the respondents (77.6\%) replied that they store drugs in out of manufacturer's direction and only $22.4 \%$ of them do not store after they bought.

\begin{tabular}{|c|c|c|c|c|}
\hline $\begin{array}{l}\text { S. } \\
\text { no }\end{array}$ & Questions & $\begin{array}{l}\text { Response } \\
\text { Categories }\end{array}$ & Frequency $(\mathrm{N})$ & Percentage \\
\hline \multirow{2}{*}{1} & \multirow{2}{*}{$\begin{array}{l}\text { Have you faced } \\
\text { anthelmintic drug } \\
\text { quality problem? }\end{array}$} & Yes & 104 & 27.1 \\
\hline & & No & 280 & 72.9 \\
\hline \multirow{3}{*}{2} & \multirow{3}{*}{$\begin{array}{l}\text { In which season } \\
\text { you buy? }\end{array}$} & Summer & 292 & 76 \\
\hline & & Spring & 83 & 21.6 \\
\hline & & Autumn & 9 & 2.4 \\
\hline \multirow{2}{*}{3} & \multirow{2}{*}{$\begin{array}{l}\text { Awareness about } \\
\text { drug store }\end{array}$} & Yes & 298 & 77.6 \\
\hline & & No & 86 & 22.4 \\
\hline \multirow{2}{*}{4} & \multirow{2}{*}{$\begin{array}{l}\text { How do you keep } \\
\text { the drug? }\end{array}$} & $\begin{array}{l}\text { On the shelf in } \\
\text { their house }\end{array}$ & 301 & 78.3 \\
\hline & & $\begin{array}{l}\text { Anywhere in } \\
\text { house }\end{array}$ & 83 & 21.7 \\
\hline \multirow{2}{*}{5} & \multirow{2}{*}{$\begin{array}{l}\text { Source of } \\
\text { information about } \\
\text { drug } \\
\text { administration? }\end{array}$} & Professional & 336 & 87.5 \\
\hline & & From leaflet & 48 & 12.5 \\
\hline \multirow{3}{*}{6} & \multirow{3}{*}{ Where do you buy? } & Vet Clinic & 228 & 59.4 \\
\hline & & $\begin{array}{l}\text { Open market and } \\
\text { vender }\end{array}$ & 129 & 33.6 \\
\hline & & Drug pharmacy & 27 & 7 \\
\hline
\end{tabular}

\begin{tabular}{|c|c|c|c|c|}
\hline \multirow{2}{*}{7} & \multirow{2}{*}{$\begin{array}{l}\text { Who conduct to } \\
\text { administer the } \\
\text { drugs? }\end{array}$} & Non Professional & 332 & 86.5 \\
\hline & & Professional & 52 & 13.5 \\
\hline \multirow{2}{*}{8} & \multirow{2}{*}{ Do you deworm? } & Yes & 360 & 93.8 \\
\hline & & No & 24 & 6.2 \\
\hline \multirow{3}{*}{9} & \multirow{3}{*}{$\begin{array}{l}\text { Frequency } \\
\text { deworming? }\end{array}$} & $\begin{array}{l}\text { For production } \\
\text { and as growth } \\
\text { promoter }\end{array}$ & 247 & 63.3 \\
\hline & & 3-4 Months & 93 & 24.2 \\
\hline & & Treat Diseased & 44 & 11.5 \\
\hline \multirow{2}{*}{10} & \multirow{2}{*}{$\begin{array}{l}\text { Knowledge about } \\
\text { dose calculation? }\end{array}$} & $\begin{array}{l}\text { Guess based on } \\
\text { age and size }\end{array}$ & 278 & 72.4 \\
\hline & & $\begin{array}{l}\text { Advice from } \\
\text { professional }\end{array}$ & 106 & 27.6 \\
\hline \multirow{2}{*}{11} & \multirow{2}{*}{$\begin{array}{l}\text { Are you aware of } \\
\text { drug withdrawn } \\
\text { Period? }\end{array}$} & Yes & 271 & 69.6 \\
\hline & & No & 113 & 30.4 \\
\hline \multirow{2}{*}{12} & \multirow{2}{*}{$\begin{array}{l}\text { Do you administer } \\
\text { over dose (to } \\
\text { relieve pain in short } \\
\text { time)? }\end{array}$} & Yes & 110 & 28.8 \\
\hline & & No & 274 & 71.2 \\
\hline \multirow{4}{*}{13} & \multirow{4}{*}{$\begin{array}{l}\text { Over } \\
\text { response? }\end{array}$} & Severe Diarrhea & 61 & 15.8 \\
\hline & & Inappetance & 29 & 7.5 \\
\hline & & Death & 18 & 4.9 \\
\hline & & No Problem & 276 & 71.8 \\
\hline \multirow{2}{*}{14} & \multirow{2}{*}{$\begin{array}{l}\text { Do you administer } \\
\text { under dose? }\end{array}$} & Yes & 88 & 22.9 \\
\hline & & No & 296 & 77.1 \\
\hline \multirow{3}{*}{15} & \multirow{3}{*}{$\begin{array}{l}\text { Responses } \\
\text { under dosing? }\end{array}$} & Cure & 60 & 15.6 \\
\hline & & Not Cured & 25 & 6.5 \\
\hline & & Doubtful & 299 & 77.9 \\
\hline \multirow[b]{2}{*}{16} & \multirow{2}{*}{$\begin{array}{l}\text { Route } \\
\text { Administration? }\end{array}$} & Oral (drenching) & 308 & 80 \\
\hline & & $\begin{array}{l}\text { Subcutaneous } \\
\text { (Injectable) }\end{array}$ & 76 & 20 \\
\hline \multirow[t]{2}{*}{17} & \multirow[t]{2}{*}{ Public Challenges? } & $\begin{array}{l}\text { Distance, } \\
\text { management } \\
\text { and working } \\
\text { schedules }\end{array}$ & 272 & 70.6 \\
\hline & & $\begin{array}{l}\text { Shortage of drug } \\
\text { and equipment }\end{array}$ & 114 & 29.4 \\
\hline \multirow[b]{2}{*}{18} & \multirow[b]{2}{*}{ Private Challenges } & High cost service & 292 & 75.8 \\
\hline & & $\begin{array}{l}\text { Inadequate } \\
\text { qualification and } \\
\text { non-professional } \\
\text { involvement }\end{array}$ & 94 & 24.2 \\
\hline
\end{tabular}

Table 2: Respondent knowledge, attitude and behavior regarding anthelmintic use in animals in the district.

As the result show that most farmers, 228 (59.4\%) were bought drug from veterinary clinic and out of total respondents 129 (33.6\%) 
respondents bought drug from other venders or open and most of them $280(72.9 \%)$ didn't face drug quality problem. And the other option was they bought drug from drug pharmacy 27 (7\%) summarized in Table 2.

\section{Discussion}

Awareness and practices of farmers towards safe handling and management of veterinary drugs was assessed using a questionnaire survey to assess level of farmer's knowledge, attitude and practices on anthelminthic drug management in relation to drug quality. In this survey among a total of 384 respondents $317(69 \%)$ male and $67(31 \%)$ female were interviewed. The results obtained in this study indicate that the farmers interviewed had low knowledge and awareness on risk factors which affect drug quality, safety and its management issues. Around $77.6 \%$ of the respondents were preferred to store drug in house at room temperature on the shelf before administration. Temperature, humidity and sunlight can affect a drug during handling and storage [1]. This could be due to lack of knowledge, no training on drug use and limited capacity building in the district or the seller is not advice the farmer how they handle and use or they stand for profitable rather for quality service. This can potentially affect the drug effectiveness since these conditions collectively show improper drug handling and management issues [8].

It is in line with the research done on veterinary drugs handling, management and supply chain assessment in Afar Pastoral Region of North East Ethiopia. Some products must be stored in a refrigerator and others do not need to be refrigerated, but must be kept below a specified temperature [16]. This finding revealed that awareness creation on drug handling and management has a positive impact on reducing the knowledge gap of the farmers. Medicinal products should be handled and transported in such a way that they are not subjected to unacceptable degrees of heat and cold [2].

Most respondents (87.5\%) explained that they capture information about prescription from professionals and some (12.5\%) said that they got from the leaflets. This reflects high awareness of people that drugs should be prescribed by the concerned persons (medics or veterinarians). It also reflects high confidence of respondents in veterinarians. Almost all respondents know that following the advice from veterinarian can increase the quality and effectiveness of the drug. This finding showed that there is a wide gap for proper and effective administration between the respondents. It described that the decisions in agriculture are based on several types of knowledge [17]. Out of 384 respondents, $278(72.4 \%)$ stated that they adjust dosage according to size and age of the individual animals and the remainder $106(27.6 \%)$ of respondents advised by professional to administer. Incorrect dosing due to inaccurate judgment of animals bodyweights and faulty dosing remains common in the district and result to compromise the quality of drugs. The unnecessary result from such practices may lead the farmers to stop drug uses by knowing that as the problem is from drug action without considering as the problem is from them.

The other most critical and unethical practice is buying drugs without prescription in which the buyers have no knowledge for what purpose the drug is going to be used. This condition facilitates the drug misuse and abuse, drug resistance and unexpected outcome in both animal and human health. This is because the purpose, dosage, method of administration, contra indication and other conditions of the drugs is not clear to the users unless it is accompanied through prescription [18].

The under dosing with anthelmintic medication has favored survival of resistant worms in animals [19]. Majority of the respondents $308(80 \%)$ drench through oral. Some anthelmintics are available in the injectable form, but most of them follow oral administration form. This practice conducted in ways of poor drenching technique, miscalculation of the correct dose volume and use of inaccurate weigh scales compounds the problem [20]. Such fault practices can down grade the quality of drugs, because even if the drug is present with active ingredient, the way of handle and use can be inactivate it. For the health and well-being of the animals under our care, it is important that treatment is given where necessary, using the most appropriate drug, dose rate and method of application [16]. Many respondents were seen to use veterinary drugs without any veterinary supervision because of the distance from clinics or their lack of availability in the existing clinics. Despite successes in different parts of the world, privatization is not necessarily free from problems [21]. They may also concentrate in and around urban areas, leaving remote rural communities isolated $[22,23]$. They may also focus solely on profit rather than providing effective quality services. The survey was in line with the survey done [21], constraints in animal health service delivery and sustainable improvement alternatives in North Gondar, Ethiopia.

Majority of the respondents replied that they use public veterinary clinic (59.4\%), the other (33.6\%) use from open market (private sector) and the rest $(7 \%)$ use from drug pharmacy. This survey was agreed with the survey done by Angesom [24] in Afar region and partially disagrees in which illegal actors sell veterinary drugs together with vegetables in local markets without any legal permission. Both of these actors sell drugs to clients and give treatment to animals. The veterinary drug supply chain starts from importers in Addis Ababa till the end users in the region. The governmental, nongovernmental and private sources get the drugs from distributors in the capital city of the country, Addis Ababa and other neighboring towns [25] this condition may not create sustainable change in the quality of drug. The reason why it had no impact on drug quality and effectiveness is that, the private veterinary service actors were mainly private veterinary drug shop owners in the town and community animal health workers in the rural areas [26].

Constraints for veterinary service delivery in the public sector were related to management, clients (livestock owners) and working schedule in government. Some of the problems related to management were may be lack of awareness, shortage of budget and drugs and also the minimal attention given to the sector. Amongst client-related problems, distance from the service center was most frequently (70.6\%) mentioned by respondents. Problems related to cost were most frequently mentioned by respondents (75.8\%) from private clinic service. Inadequate qualification and non-professional involvement practices were also mentioned by some respondents (24.2\%).

However, even if anthelmintic are correctly dispensed, knowledge and awareness of public on correct use is important for successful treatment and prevention of quality problem [27]. The results indicate that there is a problem in storing anthelmintics, mostly at room temperature [28]. Another problem indicated by this study is that many people do not stick by the right dose to be given. This is a common passive attitude; when animal owners observe any clinical improvement, they tend to interrupt treatment. Incorrect dosing is generally considered an important risk factor in affecting drug quality, 
because sub therapeutic doses might allow the survival of resistant parasite [3]. Several laboratory experiments have shown that under dosing contributes to the selection of resistant or tolerant strains. This survey was in line with the survey done by Hatem [29]. To reduce the costs of anthelmintics treatment in district, and the use of lower dosages than the recommended therapeutic ones has been advocated. Over use of anthelmintic in veterinary medicine favors the development of anthelmintic resistance [30].

In this survey, the maximum deworming was carried out in the season of summer (76\%) followed by spring (21.6\%) and autumn (2.4\%). The use of anthelmintics in different months of the year did not indicate any strategic deworming; rather it was based on the appearance of signs of parasitic diseases (11.5\%), as growth promoter (63.3\%) and strategically from 3-4 months (24.2\%). Knowledge about the use of anthelmintics as growth promoters was very satisfactory. The climatic conditions of the above season are highly favorable for the propagation of infective larvae of parasite prevalent in the study area [31]. Even if the above season is the condition for parasite revolutions and it also limit the farmers knowledge to deworm strictly on the above season in which the parasite can also survive in other condition like in marsh condition. The decision to treat, although constrained by biology and resources, is very much reliant on how the healthcare providers detect the gastrointestinal parasite and their beliefs on the best way to treat animals against the parasites. The weights of these types of knowledge are probably very different in the decision of the various healthcare providers. Knowledge is one part of the decision but values or economic resources may play a role as well [32].

In this study, we found that the majority (63\%) of the farmers was illiterate and they found it difficult to calculate the exact dose calculation per animal and as their own prescription method they depend on age and size and guessing method. During such practices they interrupt the correct dose and the correct administration way and face with bad feedback in which direct them to judge the effective drug as it is ineffective and this can compromise the quality of drug. It is because of private veterinary service is limited to towns and profitable areas, governments are unable to continue funding many goods and services, the public sector is not always efficient or effective provider of goods and services and should instead focus on policy formulation and regulation, communities had always managed their own livelihoods and natural resource base, the failure of top down approaches and the success of participatory and community based approaches [33,34]. $69.6 \%$ of respondents are aware of the anthelmintics residues in milk and meat and stick by the withdrawal period allowed for excretion of anthelmintics and (30.4\%) of respondent are not aware on withdrawal period. Nearly seventy percent of the respondents are well aware of the problem of anthelmintics residues. They are informed and agree with the withdrawal period for the removal of anthelmintics from treated animals before using their milk or meat. This reflects great understanding regarding animal health and human food safety [35].

\section{Conclusion}

Evaluation of knowledge, attitude and practices in relation to quality and management of anthelmintic drug were done through designed questionnaires and interviews. The majority of interviewed farmers was uneducated and lacks some handling and management practice of veterinary drugs to maintain the quality of drugs. The participant of the study indicated that distance of the public drug shop and the cost of the private shop had a big challenge in the study districts to purchase appropriate veterinary drug for the treatment of animal disease and that confirmed that compromise the quality of drugs. Therefore, Education and awareness creation for farmers about the drug prescription method, and the storage of drugs should be under taken and improvement of animal health service delivery through a well-regulated private service in order to mitigate the constraints apparent in the government service is mandatory in the district.

\section{References}

1. VMD (Veterinary Medicine Directorate) (2012) Assuring the Safety, Quality and Efficacy of Veterinary Medicines. Code of practice on the responsible use of animal medicine in the farm, Survey, UK. Accessed on 1 June 2017.

2. WHO (World Health Organization) (2002) Guidelines on packaging for pharmaceutical products Technical Report Series, No. 902, Geneva, Switzerland. Accessed on Feb 01, 2017.

3. WHO (World Health Organization) (2012) Rational use of medicines. World Health Organization.

4. Hussein N, Hassen A, Assayye Z (1999) Efficacy of panacure, rental and deuxamine against field infections of gastrointestinal parasites in goats. In Proceeding of Veterinary Association (EVA), 11th annual Conference, Addis Ababa, Ethiopia, pp: 15-19.

5. Kumsa B, Wossene A (2006) Efficacy of albendazole and tetramisole anthelmintics against Haemonchus contortus in experimentally infected lambs. Int J App Res Vet Med 4: 94-99.

6. Amin AA, Kokwaro GO (2007) Antimalarial drug quality in Africa. J Clin Phar Ther 32: 429-440.

7. Lon CT, Tsuyuoka R, Phanouvong S, Nivanna N, Socheat D, et al. (2006) Counterfeit and substandard antimalarial drugs in Cambodia. Trans $\mathrm{R}$ Soc Trop Med Hyg 100: 1019-1024.

8. Taylor J (2001) Recommendations on the control and monitoring of storage and transportation temperatures of medicinal products. Pharm J 267: 128-131.

9. Jansen J, Over HJ, van-Olm PW (1992) Distribution and impact of helminth diseases of livestock in developing countries. Food Agri Org Rome, Italy.

10. Gasbarre LC, Smith LL, Lichtenfels JR, Pilitt PA (2009) The identification of cattle nematode parasites resistant to multiple classes of anthelmintics in a commercial cattle population in the US. Vet Parasitol 166: 3-4.

11. De Graef J, Claerebout E, Geldhof P (2013) Anthelmintic resistance of gastrointestinal cattle nematodes. Flemish Vet J 82: 113.

12. Abuga KO, Mwagiru PM, Thoith GN, Nguyo JM, Ngugi JK, et al. (2003) Quality of Antiretroviral Drugs Analyzed in the Drug Analysis and Research Unit During 2000-2003. African J Pharm Sci 6: 20-23.

13. United States Pharmacopeia (2002) Journal of Pharmacopeial Convention 28: 654-768.

14. Kibwage IO (2008) Counterfeiting of drugs and the necessity of Quality control systems in developing countries. Katholieke Universiteit Leuven, pp: 20-23.

15. National Meteorological Agency of Ethiopia (NMA) (2011) Annual climate bulletin.

16. Brightling T, Chapman C, Reeves P (2004) Livestock exports. Best practice use of veterinary drugs. Meat and Livestock, Australia.

17. Nicourt C, Salmona M (1994) Suffering and resistance of French peasants. L'Harmattan, Paris, p: 254.

18. Gidada N (2012) Prescription and Dispensing of Veterinary Drugs. Veterinary Drug and Feed Administration and Control Proclamation. Federa Negarit Gazeta, 14: 6271.

19. Geerts S, Gryseels B (2002) Anthelmintic resistance in human helminths: A review. Trop Med Int Health 6: 915-921.

20. National Animal Disease Information Service (NADIS) (2017) Anthelmintic Resistance on Sheep Farms. 
Citation: Duguma B, Abera B, Muktar Y, Adugna S, Kefyalew H, et al. (2018) Knowledge, Attitude and Practices about Quality and Management of Anthelmintic Drugs in Adea Berga District, Central Ethiopia. J Vet Sci Technol 9: 540. doi:10.4172/2157-7579.1000540

Page 6 of 6

21. Kebede H, Melaku A, Kebede E (2014) Constraints in animal health service delivery and sustainable improvement alternatives in North Gondar, Ethiopia. Onderstepoort J Vet Res 81: 713.

22. Sen A, Chander M (2003) Privatization of veterinary services in developing countries: A review. Trop Anim Health Prod 35: 223-236.

23. Cheneau Y, Idrissi AH, Ward D (2004) An assessment of the strength and weaknesses of current veterinary systems in the developing world. Rev Sci Tech 23: 351-359.

24. Angesom HD (2015) Veterinary Drugs Handling, Management and Supply Chain Assessment in Afar Pastoral Region of North East Ethiopia. Ame J Biosci Bioeng 3: 142-148.

25. Zewdie S (2004) Animal Health Services Delivery in Ethiopia. In Proceedings of the 18th Annual Conference of the Ethiopian Veterinary Association (EVA), held in Addis Ababa, Ethiopia, pp: 51-55.

26. Australian Veterinary Association (AVA) (2005) Guidelines for Prescribing, Authorizing and Dispensing Veterinary Medicines. Version 1.0, Kingston ACT 2604, Australia. Accessed on May 25, 2017.

27. Admasu B (2010) History of Community Animal Health Service Delivery: Current Scenario and Significance of Community Animal Health Network and Its Expected Outcomes. Proceeding of the CAHNET-Ethiopia Launching Work Shop Held at Ghion Hotel, Addis Ababa, Ethiopia.

28. Food and Drug Administration (FDA) (2013) Guidance for Industry and Stability Testing of Drug Substances and Products.
29. Hatem A, Shalaby (2013) Anthelmintics Resistance; How to Overcome it? Iranian Journal of Parasitology 8: 18-32.

30. Geary TG, Woo K, Mccarthy JS, Mackenzie CD, Horton J, et al. (2010) Unresolved issues in anthelmintic pharmacology for helminthiases of humans. Int J Parasitol 40: 1-13.

31. Lateef M, Iqbal Z, Jabbar A, Khan MN, Akhtar MS, et al. (2005) Epidemiology of trichostrongylid nematode infections in sheep under traditional husbandry system in Pakistan. Int J Agri Biol 7: 596-600.

32. Cabaret J, Benoit M, Laignel G, Nicourt C (2009) Current management of farms and internal parasites by conventional and organic meat sheep French farmers and acceptance of targeted selective treatments. Vet Parasitol 164: 21-29.

33. Abebe G (2003) Community-based animal health services delivery in Ethiopia. Experiences and the way forward on community-based animal health service delivery in Ethiopia. Proceedings of a workshop held in Addis Ababa, Ethiopia.

34. Admassu B (2003) Primary Animal Health Care in Ethiopia: The experience so far. J African Union-Inter African Bur Anim Resour: 1-13.

35. Wolstenholme AJ, Fairweather I, Prichard R, von Samson-Himmelstjerna G, Sangster NC (2004) Drug resistance in veterinary helminthes. Trends Parasitol 20: 469-476. 